\title{
Chemoprophylaxis of respiratory infections
}

\author{
JOHN BATTEN \\ M.D., F.R.C.P. \\ St George's and the Brompton Hospitals
}

\begin{abstract}
Summary
Chemoprophylaxis of certain respiratory infections has been described. The benefit and cost of chemoprophylaxis of tuberculosis have been compared and indications outlined. While some protection against influenzal infection by drugs of the adamantane group has been demonstrated, chemoprophylaxis against respiratory virus infections is as yet unavailable or impractical. In diseases associated with impaired bronchial clearance the influence of long term chemoprophylaxis on the natural history of the disorders becomes less certain. Morbidity in chronic bronchitis and bronchiectasis may be reduced. In cystic fibrosis, however, although the prognosis has been undoubtedly improved by chemoprophylaxis, the effects of long term treatment of infection in the later stages are uncertain.
\end{abstract}

\section{Chemoprophylaxis of tuberculosis}

Prevention of tuberculosis by chemotherapy has been recognized for 25 years or more-world-wide studies have confirmed its practicability and efficacy and have now defined its limitations-few of these studies have been carried out in the U.K.

\section{Primary chemoprophylaxis (prevention of infection)}

This is desirable in certain tuberculin-negative individuals who have been in contact with infectious patients. The obvious example is the child under 3 or 4 years of age where the risk of miliary and meningeal tuberculosis is such as to demand immediate prevention. Experimental and clinical evidence summarized by Lambert (1959) contrasts the benefit of immediate protection that chemoprophylaxis confers, with the disadvantage due to the failure of immunity to develop or to be maintained. Organisms, however few, which become implanted in the tissues may grow only when the chemotherapy is stopped. Two of four cases of infant contacts of tuberculous parents given isoniazid subsequently developed cutaneous sensitivity to tuberculin and one of these developed active pulmonary tuberculosis (Le Long et al., 1954). This undesirable consequence of chemoprophylaxis with isoniazid can now be prevented by vaccination with isoniazid-resistant B.C.G.
(Bacille Calmette-Guérin) at the same time affording a degree of immunity which will persist after stopping the chemoprophylaxis. Isoniazid-resistant B.C.G. is as effective as B.C.G. in protecting guineapigs (Bretey and Canetti, 1957; Schaefer, Cohn and Middlebrook, 1957) and is useful in man in the same situation as described above. Isoniazid prophylaxis should be given for 3-6 months.

\section{Secondary chemoprophylaxis (treatment of infection)}

Until recently the application of secondary chemoprophylaxis has been limited in the U.K. and confined to certain small well defined groups, i.e. tuberculin-positive children under 3 years of age; recent converters and strongly positive reactors; in particular, contacts-short term contacts, positive reactors with immune-deficiency or undergoing immune suppression.

Isoniazid has made this approach possible and, to date, all chemoprophylaxis has been with this drug. It is cheap, palatable and is taken once daily by mouth: extension of its use has been limited by hitherto unknown factors: development of drug resistance; efficacy; practicability; toxicity and possible carcinogenesis.

Extensive trials reviewed by Ferebee (1969) and the American Thoracic Society (1974) have removed some of the uncertainties in this use of isoniazid which has usually been given in a dose of $300 \mathrm{mg}$ /day to adults $(10 \mathrm{mg} / \mathrm{kg}$ up to $300 \mathrm{mg}$ in children) for one year.

(1) Drug resistance even in mass community prophylaxis has been negligible.

(2) Overall effectiveness. There has been $50-70 \%$ reduction in tuberculosis morbidity and this persists for at least 15 years-probably for a lifetime (Comstock, Woolpert and Baum, 1974).

(3) Practicability. With adequate administration machinery and enthusiasm, widespread chemoprophylaxis has proved feasible. Failure to take the tablets is of course the major factor militating against complete success. Comstock et al. (1974) found that the 9-year case rate of tuberculosis following chemoprophylaxis did not rise until less than $50 \%$ of the annual recommended dose was taken. This raises the 
possibility of reduction in duration of chemoprophylaxis to 6 months.

(4) Toxicity of isoniazid has been almost wholly confined to the liver-sex incidence in whites is equal-it is less frequent in black males in the U.S.A. There is in that country a remarkable increase in liver toxicity during 1 year's treatment with increasing age. There were 1.3 cases of established hepatic toxicity per 1,000 patients treated at age 25 , rising to $17 \cdot 5$ cases at age 55 . Hepatitis rarely developed under the age of 20 (Comstock and Edwards, 1975). There are no comparable figures for the U.K. but there is no reason to doubt the phenomenon. Risks during pregnancy seem negligible and there is no evidence as yet that the risks of neoplasia are important either.

With these facts from the U.S.A. and Europe available what are the indications for isoniazid chemoprophylaxis in the U.K.? The following have been proposed by the Joint Tuberculosis Committee of the British Thoracic and Tuberculosis Association (1973):

(1) All children with positive tuberculin reactions (Heaf grades III and IV) (approximate risk of disease $2 / 1,000$ per year).

(2) All adult positive tuberculin reactors who are close contacts (approximate risk of disease $5 \%$ per year).

(3) All adult positive tuberculin reactions with inactive disease on chest X-ray (approximate risk $0.75 \%$ per year).

(4) Asian immigrants with moderate to strong tuberculin reactions. In 1971 immigrants constituted $5 \%$ of the population and $32 \%$ of notifications. Thus, those from Pakistan have fifty-five times and those from India twenty-seven times the rate of notification compared with those born in the U.K.

To these should be added (and are included in recommendations by the American Thoracic Society, 1974): (a) recent converters who have a $5 \%$ risk of active disease in the first year; (b) positive reactors with immune deficiency, immunosuppressive or adrenocorticosteroid therapy, diabetes, silicosis and post-gastrectomy.

A further factor which has to be taken into account is the cost of chemoprophylaxis of tuberculosis. Moulding (1971) by an ingenious and probably valid formula calculated the number who need to be treated to prevent one case of active tuberculosis amongst various risk categories. This varied from $14 \cdot 2$ persons with inactive pulmonary tuberculosis to 163.4 tuberculin-positive adults with normal chest radiographs. The cost of preventing one such case in the U.S.A. varied in 1971 from $\$ 824$ in the first instance to $\$ 7,026$ in the second. Assuming approximately similar conditions in the U.K. in 1975, the benefit achieved by treating 143 positive tuberculin reactors with normal chest X-rays in order to prevent one case would be questioned on any grounds, let alone cost. But cost does enter into the consideration of isoniazid prophylaxis in tuberculin-positive adolescents with a normal chest radiograph which in 1971 in the U.S.A. would have cost \$4,743-approximately that of treating one case of active pulmonary tuberculosis-while exposing 110 adolescents to the inconvenience of isoniazid prophylaxis.

Those people with liver disease and alcoholism, those who have had previous treatment for tuberculosis or who are receiving phenytoin, should be excluded. No routine screening is necessary but new symptoms should be reported immediately and isoniazid should be stopped if a three-fold rise in aminotransferases is found.

\section{Chemoprophylaxis in respiratory virus infection}

Virus infections of the respiratory tract are a very common cause of illness and loss of time from work and although there are variations in susceptibility to one virus or another according to age, in general they attack normal individuals as well as those with host abnormalities. Successful prevention would bring enormous benefit to the community at large. While vaccines have been developed with some success in influenza, they are so far unavailable or impractica against the vast range of viruses capable of causing respiratory tract infection. The discovery of poten antiviral chemoprophylaxis would therefore seent more likely to succeed. This would be of particular value to patients with disorders such as chronic bronchitis and bronchiectasis in whom local defence mechanisms are at fault, and in whom virus infection is presumed to precede bacterial growth during most exacerbations.

Most substances so far examined for antiviral activity are too toxic, or lacking in potency for preventing respiratory disease in man (Inglot, 1973). On the one hand, interferon given locally can be found to exert some detectable effects on infection with influenza B virus and certain rhinovirus infections. True chemoprophylaxis, on the other hand, has been found to exert significant protection. Thus, amantidine afforded $52 \%$ protection in a control field trial amongst 391 medical students in an influenza A2 epidemic in Helsinki in 1969 (Oker Blom et al., 1970). A new adamantane compound, a 1-methylspiro derivative, caused fewer symptoms, lesser antibody rise and virus excretion than a placebo in a double-blind controlled study, in protection against challenge with a Hong Kong/68 virus. It appeared on the evidence available to be more effective than either amantidine or rimantidine (Beare, Hall and Tyrell, 1972). While viral chemoprophylaxis has little to offer at present there seems reasonable hope that further developments may bring effective agents. 
Secondary bacterial infection in rhinovirus infections (common cold) are common. A significant reduction in duration of symptoms after giving tetracycline $15 \mathrm{mg}$ twice daily for 3 days after the appearance of prodromal symptoms was reported by Ritchie (1958) and confirmed by McKerrow, Oldham and Thomson (1961). Such prophylaxis cannot be contemplated on a large scale but is reserved for high risk patients with cardio-respiratory problems.

\section{Chemoprophylaxis with impaired bronchopulmonary clearance \\ Chronic bronchitis \\ While bacterial infection plays an uncertain role in} the cause and the progress of chronic bronchitis and emphysema, there seems little doubt that purulent exacerbations are major causes of morbidity with functional deterioration and, in advanced cases, lead to cardiorespiratory failure and death. In less severe cases, recurrent infections are responsible for disabling illness. While Haemophilus influenzae and pneumococci are recognized pathogens, the correlation of their appearance in the sputum with exacerbations is far from close. Routine examinations of the sputum for purposes of prevention or treatment are therefore of doubtful value. A primary cause of deterioration is usually a virus infection but other factors such as environmental pollutants may be involved.

Chemoprophylaxis aimed at bacteriostasis (May, 1972) reduces the severity of episodes of acute purulent bronchitis (Francis and Spicer, 1960; Francis, May and Spicer, 1961, 1964; Medical Research Council, 1966). While duration of episodes was reduced in these and other studies (May, 1972; Darke, Weber and Beeley, 1972) their frequency was unaffected, suggesting that the bacterial component of each episode was secondary to some other cause. That this is not always the case, however, is the conclusion of two studies (Buchanan et al., 1958; Johnston et al., 1969) in which the frequency of exacerbations was reduced. Whatever impact chemoprophylaxis may have on episodes of purulent bronchitis there is, thus far, no evidence that progression of the disease with deterioration of lung function is modified.

Long term continuous prophylaxis is to be recommended for patients with chronic bronchitis (and/or emphysema) who have had two or more disabling attacks of purulent bronchitis in preceding winters. Frequent recourse to short periods of treatment is more likely to encourage drug resistance (May, 1972). Continuous treatment on the other hand is rarely associated with development of drug resistance amongst the major pathogens $H$. influenzae and Streptococcus pneumoniae. It should be noted, however, that the prevalence of pneumococcal strains resistant to tetracycline is increasing (Percival, Armstrong and Turner, 1969; Holt, Evans and Newman, 1969). Tetracycline, ampicillin, amoxicillin (250-500 $\mathrm{mg}$ twice a day) or trimethoprim $(160 \mathrm{mg}) /$ sulphamethoxazole $(800 \mathrm{mg})$ (co-trimoxazole) twice daily are almost equally effective in the proportion of patients gaining benefit. Failure of one drug would be an indication for the trial of another. This approach, however, should be abandoned if disabling purulent bronchitis is not clearly ameliorated or eliminated in the winter months. Established Gram-negative infection, rare as it is in chronic bronchitis, is not susceptible to chemoprophylaxis.

This form of treatment is expensive (oxytetracycline is the cheapest variant) and in many cases immediate treatment of exacerbations is preferable. A controlled trial has, however, shown poorer results when patients are instructed to take the drug at the beginning of an acute episode rather than on a continuous basis (British Tuberculosis Association, 1961).

\section{Bronchiectasis and cystic fibrosis}

While $H$. influenzae is also a very common pathogen in these disorders which are associated with bronchopulmonary suppuration, other bacterial species, notably Staphylococcus aureus and Pseudomonas aeruginosa are frequently found. The ability of $\boldsymbol{H}$. influenzae to infect the lung so frequently in chronic bronchitis and of Staph. aureus and Pseudomonas to do so in bronchiectasis and cystic fibrosis poses fundamental and unanswerable questions as to the nature of the impairment of host defence in these conditions.

Precipitating antibodies are of recognized importance in discriminating between true pathogens and the many other organisms found in the sputum.

Bronchiectasis. $H$. influenzae is the most important pathogen-Burns and May (1967) reported that $88 \%$ of patients have precipitating antibody of the specific $\mathrm{H}_{1}$ variety compared with $6 \%$ of controls. Thus chemoprophylaxis should be similar to that for chronic bronchitis. Tetracycline, $500 \mathrm{mg}$, four times on two days of each week was effective in reducing sputum quantity, cough and loss of time from work in a controlled study (Medical Research Council, 1957). A trial of such preventive treatment is justified in severe bronchiectasis-daily treatment in the same dose may be more successful. As with chronic bronchitis, it is usually preferable to treat acute exacerbations, as $30 \%$ of patients have staphylococcal or pneumococcal infection, these organisms should be suppressed by a trial of the most appropriate agent in patients with persistent symptoms and disability. The appearance of mucoid strains of Pseudomonas and Klebsiella in the sputum 
is usually followed by specific antibodies in the serum. These organisms are important pathogens but are not susceptible to chemoprophylaxis. Other Gram-negative bacteria are not associated with serum antibodies and are probably non-invasive (Burns, 1968; Burns and May, 1968). All chemoprophylaxis should be supplementary to postural coughing and percussion.

Cystic fibrosis. Bacterial infection in the lung which has been reviewed by Mearns, Hunt and Rushworth (1972), May, Herrick and Thompson (1972) and Hoiby (1974) presents the ultimate challenge to antibacterial chemoprophylaxis and chemotherapy. Eighty per cent of children with this disease died in the first year of life, usually with overwhelming staphylococcal disease of the lung, when first reported by Anderson (1938). Since then there have been striking changes in life expectancy, especially since the advent of potent oral antistaphylococcal drugs-nowadays the mean survival in the best centre exceeds 12 years from diagnosis. The widespread use of these agents has also been associated with a fundamental change in the environmental bacterial flora especially in hospitals. Pseudomonas spp. are more prevalent-staphylococcal much less so.

In cystic fibrosis the newborn airways are structurally normal and are free of infection. In the majority, mucus gland hypertrophy and goblet cell proliferation go hand in hand with the development of bronchopulmonary infection soon after birth: but the relation of one to the other is uncertain. Pseudomonas has emerged as a primary bacterial pathogen and is now isolated more often than Staph. aureus in childhood (Mearns et al., 1972). $H$. influenzae, which is also isolated more frequently with increasing age, may represent an opportunistic invader. Radiological abnormalities may appear in the absence of bacteria in the sputum or serum antibodies which raises the possibility of virus infection or other triggers to the bronchopulmonary disease.

Once infection is established, one or other of these pathogens is always to be found in the sputum despite appropriate chemotherapy in high dose-the organisms usually retain their susceptibility in vitro.

Primary bacterial chemoprophylaxis, aimed at preventing initial infection, with cloxacillin and ampicillin at least for the first year after diagnosis appears logical at first sight but is usually unsuccessful, only in part because of the resistance of Pseudomonas.

Secondary prophylaxis to reduce the bacterial populations and prevent the development of progressive disease is widely practised (either continuously or with acute infections) in association with vigorous physical methods aimed at bronchopulmonary clearance. While this approach has undoubtedly been associated with an improved prognosis, the effect of chemoprophylaxis in the later stages of the disease is as uncertain as it is in severe chronic bronchitis: factors other than infection may be responsible for progressive impairment of structure and function which seem invariable. Controlled trials of antibacterial chemoprophylaxis and therapy are needed.

\section{Conclusion}

The benefits of chemoprophylaxis of respiratory infection are obvious in certain individuals aud groups at risk of developing active tuberculosis. These benefits become much less certain when host defences are compromised as in chronic bronchitis, bronchiectasis and cystic fibrosis. The inadequacy of chemoprophylaxis in disorders in which bacterial infection is clearly present, is ill understood but nonbacterial infection and as yet unidentified factors presumably militate against the antimicrobial activity.

\section{References}

American Thoracic Society (1974) Preventive treatment of tuberculous infection. American Review of Respiratory Disease, 110, 371.

ANDERSON, D.H. (1938) Cystic fibrosis of the pancreas and it relation to celiac disease: a clinical and pathologicat. study. American Journal of Diseases of Children, 56, 344

Beare, A.S., Hall, T.S. \& TYrell, D.A.J. (1972) Protection? of volunteers against challenge with A/Hong Kong/68 influenza virus by a new adamantane compound. Lancet, i, 1039.

BRETEY, J. \& CANETTI, G. (1957) Effect of early administration of isoniazid in the immunizing activity of normal B.C.G. and isoniazid-resistant B.C.G. in guinea-pigs. American Review of Tuberculosis, 75, 650.

British Tuberculosis Association (1961) Chemotherapy of bronchitis. Influence of penicillin or tetracycline administered daily, or intermittently for exacerbations. British Medical Journal, 2, 979.

Buchanan, J., Buchanan, W.W., Melrose, A.G., McGuinness, J.B. \& Price, A.V. (1958) Long term prophylactic administration of tetracycline to chronic bronchitis. Lancet, ii, 719.

BuRns, M.W. (1968) Precipitins to Klebsiella and other enterobacteria in the serum of patients with chronic respiratory disorders. Lancet, i, 383.

BuRNS, M.W. \& MAY, J.R. (1967) Haemophilus influenzae precipitins in the serum of patients with chronic bronchial disorders. Lancet, i, 354.

BURNS, M.W. \& MAY, J.R. (1968) Bacterial precipitins in the serum of patients with cystic fibrosis. Lancet, $\mathrm{i}, 270$.

Comstock, G.W. \& Edwards, P.Q. (1975) The competing risks of tuberculosis and hepatitis for adult tuberculin reactors. American Review of Respiratory Disease, 111, 573.

Comstock, G.W., Woolpert, S.F. \& BAUM, C. (1974) Isoniazid prophylaxis among Alaskan Eskimos. A progress report. American Review of Respiratory Disease, 110, 195.

Darke, C.S., Weber, J.C.P. \& Beeley, J.M. (1972) Sulfametopyrazine in the prophylaxis of exacerbations of chronic bronchitis. British Journal of Diseases of the Chest. 66, 276. 
Ferebee, S.H. (1969) Controlled chemoprophylaxis trials in tuberculosis. A General Review. In: Advances in Tuberculosis Research, Vol. 17, p. 28. S. Karger, Basel, New York.

Francis, R.S., May, J.R. \& SPICER, C.C. (1961) Chemotherapy in chronic bronchitis. Influence of penicillin and tetracycline administered daily, or intermittently for exacerbations. British Medical Journal, 2, 979.

Francis, R.S., MaY, J.R. \& SPICER, C.C. (1964) Influence of daily penicillin, tetracycline, erythromycin and sulphamethoxypyridazine on exacerbations of bronchitis. British Medical Journal, 1, 728.

Francis, R.S. \& SPICER, C.C. (1960) Chemotherapy in chronic bronchitis. Influence of daily penicillin and tetracycline on exacerbations and their cost. British Medical Journal, 1, 297.

HolBy, N. (1974) Epidemiological investigations of the respiratory tract bacteriology in patient with cystic fibrosis. Acta pathologica et microbiologica scandinavica, Section B, 82, 541 .

Holt, R., Evans, T.N. \& Newman, R.L. (1969) Tetracyclineresistant pneumococci. Lancet, ii, 545.

INGLOT, A.D. (1973) Anti-viral drugs in human therapy. Acta microbiologica polonica, 5, 183.

Johnston, R.N., McNeill, R.S., Smith, D.H., Dempster, M.B., NaIrN, J.R., Purvis, M.S., Watson, J.N. \& Ward, F.G. (1969) Five year winter chemoprophylaxis for chronic bronchitis. British Medical Journal, 4, 265.

Joint Tuberculosis Committee (1973) Chemoprophylaxis against tuberculosis in Britain. Tubercle, 54, 209.

LAMBERT, H.P. (1959) Chemoprophylaxis of tuberculosis. A Review. American Review of Respiratory Diseases, 80, 648.

le Long, M., Alison, F., Meyer, B. \& Celeris Bourrillon, J. (1954) Essais de traitement du nouveau-né dès la période anti-allergique. Archives françaises de pédiatrie, 11, 895.
McKerrow, C.B., Oldham, P.D. \& Thomson, S. (1961) Antibiotics and the common cold. Lancet, i, 185.

MAY, J.R. (1972) Chemotherapy of chronic bronchitis and allied disorders, 2nd Edn. The English Universities Press, London.

May, J.R., Herrick, N.C. \& Thompson, D. (1972) Bacterial infection in cystic fibrosis. Archives of Disease in Childhood, 47, 908.

Mearns, M.B., Hunt, G.H. \& Rushworth, R. (1972) Bacterial flora of respiratory tract in patients with cystic fibrosis, (1950-71). Archives of Disease in Childhood, 47, 902.

Medical Research Council (1957) Prolonged treatment of severe bronchiectasis. British Medical Journal, 2, 255.

Medical Research Council (1966) Value of chemoprophylaxis and chemotherapy in early chronic bronchitis. A report to the Medical Research Council by their Working Party on trials of chemotherapy. British Medical Journal, $1,1317$.

Moulding, T.M. (1971) Chemoprophylaxis of tuberculosis. When is the benefit worth the use and the cost? Annals of Internal Medicine, 74, 761.

Oker-Blom, N., Hovi, T., Lenniki, P., Palosno, T., PetterSON, R. \& Sumi, J. (1970) Protection of man from natural infection with Influenza $\mathrm{A} 2 /$ Hong Kong virus by amantidine. A controlled trial. British Medical Journal, 3, 676.

Percival, A., Armstrong, E.C. \& Turner, G.C. (1969) Increased incidence of tetracycline-resistant pneumococci in Liverpool in 1968. Lancet, i, 998.

Ritchie, J.M. (1958) Antibiotics in small doses for the common cold. Lancet, i, 615.

Schaefer, W.B., Cohn, M.L. \& Middlebrook, G. (1957) Comparative study of the vaccinating properties of B.C.G. and its isoniazid-resistant mutant in guinea-pigs. American Review of Tuberculosis, 75, 656. 